\title{
Dual Serotonin (5-HT) Projections to the Nucleus Accumbens Core and Shell: Relation of the 5-HT Transporter to Amphetamine- Induced Neurotoxicity
}

\author{
Pierre Brown ${ }^{1}$ and Mark E. Molliver ${ }^{1,2}$ \\ Departments of ${ }^{1}$ Neuroscience and ${ }^{2}$ Neurology, The Johns Hopkins University School of Medicine, \\ Baltimore, Maryland 21205
}

\begin{abstract}
Dopamine release in the nucleus accumbens (NAc) has been implicated as mediating the rewarding effects of stimulant drugs; however, recent studies suggest that 5-HT release may also contribute. In an effort to assess the role of 5-HT in drug-mediated reward, this study analyzed the serotonergic innervation of NAc using immunocytochemistry for 5-HT and the 5-HT transporter (SERT). We report that in control rats the NAc receives two distinct types of 5-HT axons that differ in regional distribution, morphology, and SERT expression. Most regions of the NAc are innervated by thin 5-HT axons that express SERT, but in the caudal NAc shell nearly all 5-HT axons lack SERT and have large spherical varicosities. Two weeks after methamphetamine or $p$-chloroamphetamine (PCA) treatment, most 5-HT axons in dorsal striatum and NAc have degenerated; however, the varicose axons in the shell appear intact. These drug-resistant 5-HT axons that lack SERT densely
\end{abstract}

innervate the caudal one-third of the accumbens shell, the same location where dopamine axons are spared after methamphetamine. Moreover, $4 \mathrm{hr}$ after PCA, the varicose axons in the caudal shell retain prominent stores of $5-\mathrm{HT}$, whereas $5-\mathrm{HT}$ axons in the rest of the NAc are depleted of neurotransmitter. The results demonstrate that two functionally different 5-HT projections innervate separate regions of the NAc and that selective vulnerability to amphetamines may result from differential expression of SERT. We postulate that action potentials conducted from the raphe nuclei can release 5-HT throughout the NAc, whereas transporter-mediated release induced by stimulant drugs is more restricted and unlikely to occur in the caudal NAc shell.

Key words: methamphetamine; p-chloroamphetamine; neurotoxicity; addiction; dopamine; 5-HT; 5-HT transporter; nucleus accumbens; striatum; reward
The nucleus accumbens (NAc) is the limbic portion of the striatum with abundant afferent and efferent connections to limbicrelated areas of the brain (Heimer et al., 1991; Brog et al., 1993) and has long been considered the principal site of action for addictive drugs. Based on the regional distribution of neuropeptides, the NAc has been divided into two subdivisions, a central core region that surrounds the anterior commissure and a more ventromedial shell region that partially encases the core $(\mathrm{Za}$ borszky et al., 1985; Voorn et al., 1989; Jongen-Relo et al., 1993, 1994; Meredith et al., 1996). Functional heterogeneity exists among the NAc subdivisions because projections from the shell are directed primarily to limbic structures, whereas the core projects to typical motor-related regions of basal ganglia (Heimer et al., 1991). Drug-induced release of dopamine (DA) in the NAc is associated with the rewarding effects of psychostimulants such as methamphetamine (Meth) and cocaine, which act at the DA transporter (DATr) (Pontieri et al., 1995; Wise, 1996; Caine, 1998; Koob et al., 1998). DA axons that arise predominantly from the ventral tegmental area (Swanson, 1982; Brog et al., 1993) densely innervate the NAc, which also receives a serotonergic (5-HT) innervation that has not been well characterized. Recently, transgenic mice lacking the DATr were found to self-

Received Aug. 31, 1999; revised Dec. 14, 1999; accepted Dec. 15, 1999.

This study was supported by US Public Health Service Grants DA 08692, DA 04431, and NO1DA 3-7301.

Correspondence should be addressed to Dr. Mark E. Molliver, Department of Neuroscience, PCTB 1018, Johns Hopkins University School of Medicine, 725 North Wolfe Street, Baltimore, MD 21205. E-mail: molliver@bs.jhmi.edu.

Copyright (C) 2000 Society for Neuroscience $0270-6474 / 00 / 201952-12 \$ 15.00 / 0$ administer cocaine, a surprising result that challenges the DA hypothesis of addiction and leads to the interpretation that 5-HT neurons may contribute to the rewarding effects of stimulant drugs (Rocha et al., 1998).

Methamphetamine and other abused drugs produce increased levels of extracellular DA in the NAc (Carboni et al., 1989; Pontieri et al., 1995) via transporter-mediated release. Meth binds to the DATr and blocks reuptake of DA and promotes reverse transport of DA across the DATr (Sulzer et al., 1993). Meth can also enter the DA terminal and release DA from synaptic vesicles into the cytoplasm by disrupting the vesicular proton gradient (Sulzer and Rayport, 1990; Sulzer et al., 1995; Jones et al., 1998). Released extracellular DA produces electrophysiological changes in striatal neurons that result in reinforcing or pleasurable drug effects. In addition to inducing "desired" recreational effects, amphetamine derivatives are neurotoxic to monoamine axons. For example, Meth causes degeneration of axon terminals in the striatum and NAc (Ricaurte et al., 1982), accompanied by decreased DA markers (Ricaurte et al., 1980). Reduced levels of striatal DA together with swollen, fragmentated axons were evident 2-3 d after repeated administration of Meth at high doses (Eisch et al., 1992; Broening et al., 1997). DA axons exhibited differential vulnerability to Meth, because axons within the dorsal striatum and the NAc core degenerated, whereas those in the NAc shell were selectively spared (Broening et al., 1997). In addition to effects on DA projections, Meth and other amphetamine derivatives also release 5-HT, followed by degeneration of 5-HT axons throughout cerebral cortex, hippocampus, and striatum (O’Hearn et al., 1988; Molliver et al., 1990; Axt and Molliver, 
1991; Mamounas et al., 1991). Two different 5-HT axon types can be distinguished (Kosofsky and Molliver, 1987), and amphetamine toxicity is highly selective for one subtype, namely thin, smooth 5-HT axons, whereas axons with large varicosities are spared (O’Hearn et al., 1988; Axt and Molliver, 1991; Mamounas et al., 1991). The consistent, differential vulnerability to substituted amphetamines suggests that 5-HT axons may express properties that determine which are vulnerable or resistant. The 5-HT transporter (SERT) plays a critical role in mediating the neurotoxicity, because blockade of SERT protects against amphetamine-induced axonal damage (Schmidt and Gibb, 1985; Fuller and Snoddy, 1986; Schmidt and Taylor, 1990). To clarify the role of 5-HT in the neurotoxic and addictive effects of amphetamines, the present study characterized the serotonergic innervation of the NAc in terms of the distribution and morphology of 5-HT axons, SERT expression, and vulnerability to amphetamine derivatives.

\section{MATERIALS AND METHODS}

Animals. Male Sprague Dawley rats (250-350 gm; Harlan Sprague Dawley, Indianapolis, IN) were used in all experiments. For the neurotoxicity studies, 12 animals were treated with saline, 12 with Meth, and 12 with PCA. To study acute 5-HT depletion ( $4 \mathrm{hr}$ survival), 8 rats received saline and 8 received PCA. Animals were housed individually in wire mesh cages within a temperature-controlled room $\left(22-24^{\circ} \mathrm{C}\right)$ on a $12 \mathrm{hr}$ light/dark cycle.

Drug treatment. Methamphetamine (Sigma, St. Louis, MO) or p-chloroamphetamine (Regis Chemical Company, Morton Grove, IL) was dissolved in saline and administered according to the following schedules (as free base): Meth, $4 \times 20 \mathrm{mg} / \mathrm{kg}$, i.p., every $2 \mathrm{hr}$; PCA, $2 \times$ $10 \mathrm{mg} / \mathrm{kg}$, i.p., $24 \mathrm{hr}$ apart. Control animals were injected with saline $(0.9 \% \mathrm{NaCl})$. The treated animals demonstrated typical amphetamineinduced responses (hyperactivity and stereotypy). Meth administration produced hyperthermia that is associated with (and necessary for) dopamine toxicity. After Meth treatment, core body temperature was monitored by radiotelemetry (Data Sciences International) and typically increased from $37-38^{\circ} \mathrm{C}$ to $40-41^{\circ} \mathrm{C}$. Because sustained body temperatures of $>41^{\circ} \mathrm{C}$ usually proved lethal, ambient room temperature was maintained between 22 and $24^{\circ} \mathrm{C}$ to keep core temperature $<41^{\circ} \mathrm{C}$ and to reduce lethality. This approach resulted in reproducible lesions of DA and 5-HT axons, with $\sim 17 \%$ lethality after Meth ( 2 of 12 animals) and zero lethality after PCA.

Fixation and tissue preparation. Two weeks (or $4 \mathrm{hr}$ ) after drug treatment, animals were anesthetized with sodium pentobarbital $(20 \mathrm{mg} / \mathrm{kg}$, i.p.) and transcardially perfused with $150 \mathrm{ml}$ of PBS, followed by $450 \mathrm{ml}$ of $4 \%$ paraformaldehyde in PBS, $\mathrm{pH}$ 7.4. Whole brains were post-fixed for $5 \mathrm{hr}$ in $4 \%$ paraformaldehyde and then cryoprotected overnight in $10 \%$ DMSO in PBS. Coronal or horizontal sections through the striatum were cut at $40 \mu \mathrm{m}$ on a freezing-sliding microtome and stored in PBS at $4^{\circ} \mathrm{C}$.

Immunohistochemistry. A series of adjacent sections from each brain were processed for immunohistochemistry, using antisera directed against 5-HT, tyrosine hydroxylase (DiaSorin Inc., Stillwater, MN); SERT [vs rat N terminus/glutathione $S$-transferase (GST) fusion protein, amino acids 1-85; catalog \#MAB1564], or DATr ( $\mathrm{N}$ terminus/GST fusion protein, catalog \#MAB369) (both from Chemicon International, Temecula, CA). Freely floating sections were incubated for $1 \mathrm{hr}$ at room temperature in a solution of PBS containing Blotto (Pierce, Rockford, IL) with $0.2 \%$ Triton X-100 (Pierce) and 2\% normal goat (5-HT) or normal horse (SERT) serum (Vector Laboratories, Burlingame, CA). Sections were then incubated overnight in primary antisera for 5-HT $(1: 20,000)$, tyrosine hydroxylase $(1: 8,000)$, SERT $(1: 10,000)$, or DATr $(1: 20,000)$ diluted in the same blocking solution. The primary antibodies were visualized using Vectastain ABC elite reagents (Vector Laboratories) and 3,3'-diaminobenzidine (Sigma). The transporter antibodies were previously characterized for specificity. The anti-DATr stained a single band on Western blot at $60-70 \mathrm{kDa}$, and immunocytochemical staining was abolished after ablation of DA projections with 6-hydroxydopamine. Specificity for the SERT antibody was well documented in a previous report using Western blots and other controls (Schroeter et al., 1997). Immunostaining for SERT selectively labels raphe neurons and their projections with no labeling of neurons in locus coeruleus or substantia nigra. The distribution of staining precisely matched that obtained with several other well characterized SERT antibodies from different sources.

Data analysis and microscopy. A series of sections through all levels of striatum were examined, and selected sections at three distinct levels through the nucleus accumbens were analyzed (corresponding approximately to interaural $11.7,11.2$, and $10.0 \mathrm{~mm}$ ) using a Leica (Nussloch, Germany) DMRB/E microscope equipped for bright-field differential interference contrast (DIC) and dark-field illumination. Highmagnification photomicrographs were made with a Leica DMLD camera, and low-magnification micrographs made with a Wild/Leica M420 Macroscope. Brain levels and anatomic landmarks were determined by matching sections to stereotaxic atlas levels (Paxinos and Watson, 1998; Swanson, 1998).

\section{RESULTS}

\section{5-HT innervation of forebrain}

To assess the general pattern of 5-HT innervation, coronal forebrain sections of control rats prepared for immunocytochemistry (ICC) with an antibody to 5-HT were examined with dark-field illumination at low magnification. Comparison of 5-HT immunostained sections with adjacent sections prepared to demonstrate the SERT showed that 5-HT axons densely innervated the entire forebrain with local differences in axon density that matched the regional pattern of 5-HT innervation previously described (Steinbusch, 1981; Steinbusch et al., 1981; O’Hearn et al., 1988; Mamounas et al., 1991). For example, 5-HT axons extended through all regions of cerebral cortex in the rat with a gradient of axon density that decreases from frontal to occipital pole (Lidov et al., 1980; Steinbusch, 1981; Blue et al., 1988; Hornung et al., 1990; Mamounas et al., 1991). A moderately dense plexus of 5-HT axons was present throughout the striatum with some regional differences in density (Steinbusch, 1981; O'Hearn et al., 1988), but the striatal 5-HT innervation pattern has not previously been characterized in detail.

Throughout cerebral cortex, the regional distribution of axons that express SERT is similar to that of axons that are immunopositive for 5-HT, as described previously (Axt et al., 1995). Subtle differences between the relative densities of 5-HT and of SERT immunostaining could be detected in particular cortical regions (e.g., in hippocampus and entorhinal cortex) and agree with differences in innervation pattern that have been observed (K. Axt, Y. Qian, R. Blakely, and M. Molliver, unpublished observations). SERT-positive axons in the striatum exhibit regional differences in distribution that are described in more detail below.

\section{5-HT-immunoreactive axons in dorsal striatum and nucleus accumbens}

The dorsal striatum received an extensive, dense innervation by 5-HT-IR axons, which are tortuous and of consistent morphology. Nearly all 5-HT axons in the caudate-putamen were smooth and uniformly thin in caliber $(0.3 \mu \mathrm{m})$, as seen with bright-field microscopy using DIC.

The NAc shell and core were readily delineated with an antibody to calbindin (data not shown), as described previously (Jongen-Relo et al., 1994; Mijnster et al., 1997). In sections prepared for 5-HT ICC at several levels (Fig. 1), both the NAc core and shell are densely innervated by serotonergic projections and stand out prominently because the 5-HT axon density in both accumbens subdivisions is greater than in dorsal striatum (Fig. $2 A)$. Furthermore, within the nucleus accumbens, the shell contains a higher density of 5-HT axons than does the core, a difference particularly evident in caudal regions of NAc (interaural $10.0 \mathrm{~mm}$ ). In addition, the density of 5-HT innervation in the 


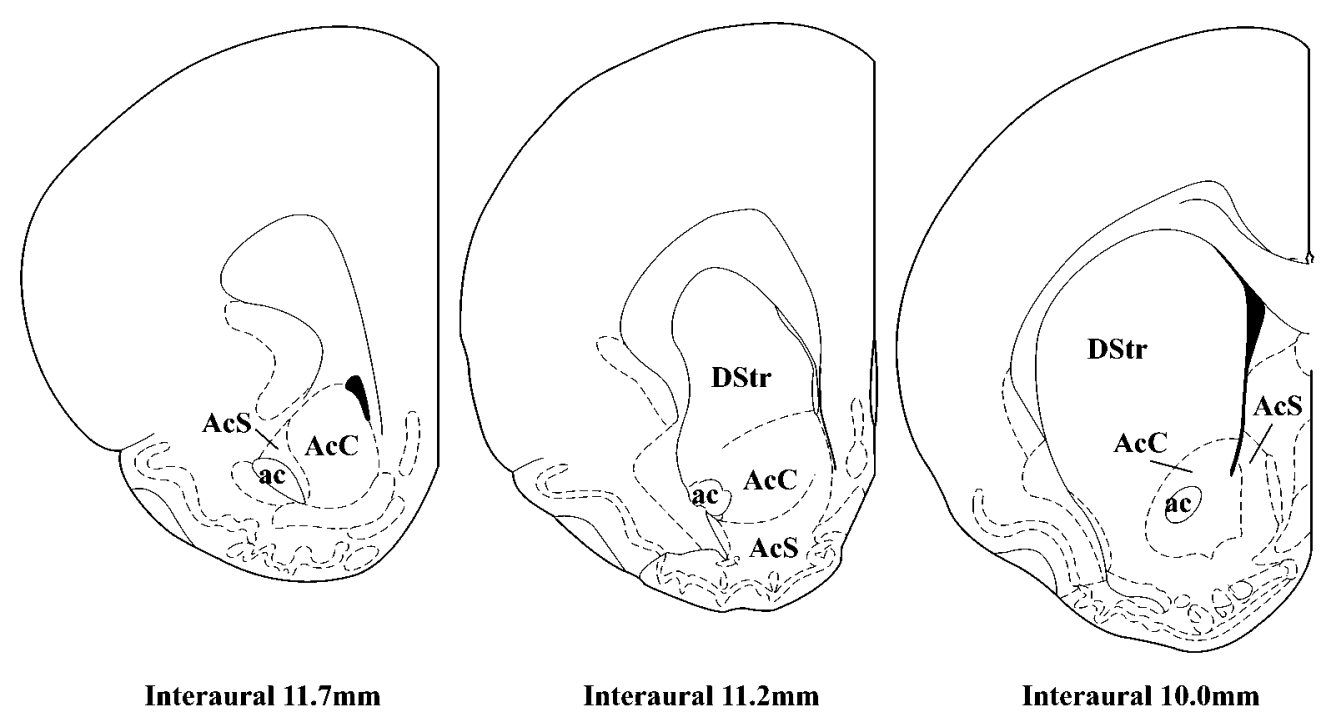

Figure 1. Drawings of three coronal levels through nucleus accumbens and dorsal striatum. Line drawings show the rostral pole (interaural $11.7 \mathrm{~mm}$ ), intermediate division (interaural $11.2 \mathrm{~mm}$ ), and caudal (interaural $10.0 \mathrm{~mm}$ ) division of the nucleus accumbens, where the serotonergic innervation was analyzed in this study (from Paxinos and Watson, 1998). ac, Anterior commissure; $A c C$, nucleus accumbens core; $A c S$, nucleus accumbens shell; DStr, dorsal striatum.

caudal one-third of the shell is considerably greater than in the rostral two-thirds. High-magnification bright-field microscopy (DIC) demonstrated that most 5-HT-IR axons in the caudal NAc shell had large, spherical varicosities (1.5-2 $\mu \mathrm{m})$ (Fig. 3A,D), and these were interspersed with a much smaller number of thin, smooth axons. Prominent differences in axon morphology distinguished the core and shell compartments: the NAc core is innervated exclusively by thin $(0.3 \mu \mathrm{m})$, smooth axons, which contrast with the larger-diameter, highly varicose 5 -HT axons $(0.5 \mu \mathrm{m}$ intervaricose segments) that predominate in the caudal shell. The most common axon types differ between the rostral and caudal shell because the rostral shell is innervated predominantly by thin, smooth 5-HT axons and receives few varicose axons. The thin 5-HT axons found in the NAc core appear morphologically identical to those that innervate the dorsal striatum.

\section{SERT-immunoreactive axons in dorsal striatum and nucleus accumbens}

Numerous axons that express SERT-IR densely innervated the entire dorsal striatum. These axons, which are thin, smooth, and tortuous, have the same morphology and density as the serotonergic axons (5-HT-IR) in dorsal striatum. SERT-IR axons were also present throughout the NAc in control rats (Fig. 2D); however, their distribution differed markedly from that of 5-HT-IR axons seen in adjacent sections. The NAc core, which surrounds the anterior commissure, contains a high density of axons that are positive for SERT, and these correspond to the densely packed 5-HT-IR axons that innervate this region. In contrast, relatively few axons in the caudal NAc shell express the serotonin transporter; as a result, in sections stained for SERT the shell subdivison appeared as a sparsely stained zone, which occupied the medial part of the nucleus accumbens (Fig. 2D). The paucity of SERT-IR axons in the caudal NAc shell contrasted with the high density of 5-HT-IR axons in this region; this difference indicates that most 5-HT axons in the caudal shell lack the 5-HT transporter. When examined with high-magnification DIC optics, all SERT-IR axons (Fig. 3E,H) were characteristically thin and smooth, and they lacked large varicosities. These SERT-positive, nonvaricose axons were located mainly in the NAc core (with some in the shell), and their morphology was distinct from the large, varicose axons in the caudal shell, which express 5-HT but not SERT (Fig. 3A,D).

\section{Effect of methamphetamine on the serotonergic innervation of the NAc}

Fourteen days after Meth treatment, 5-HT axon density was greatly reduced throughout the forebrain, including most of cerebral cortex, dorsal striatum, and the lateral part of the nucleus accumbens. In the NAc core, 5-HT-IR axons were almost completely absent; however, most 5-HT axon terminals in the caudal NAc shell were spared. In sections immunostained for 5-HT, the accumbens core and the adjacent dorsal striatum were pale and unstained (Fig. 2B). In contrast, 5-HT-positive axons remained intact in the caudal accumbens shell, where they formed a prominent zone of densely packed 5-HT-IR axons (Fig. 2B). The density of 5-HT axons in the caudal shell appeared slightly decreased compared with the density in control rats. Axon sparing was most prominent in the medial portion of the shell, because the ventrolateral extension of the shell, which curves laterally under the NAc core, revealed a moderate decrease in 5-HT axons.

In adjacent sections that showed serotonin transporter protein, no SERT-IR axons were detectable in the NAc core or shell after Meth (Fig. 2E). The entire dorsal striatum, in addition to both subdivisions of the accumbens, were devoid of SERT-IR axons. The lack of staining for the 5-HT transporter in the NAc shell, despite the presence of numerous 5-HT-IR varicose axons remaining in this region, indicates that the Meth-resistant axons do not express SERT. The slightly decreased number of 5-HT axons in the caudal shell results from loss of the few thin, SERT-IR axons located in that division.

Using high-magnification bright-field microscopy (DIC), the spared 5-HT-IR axons present in the NAc shell were characterized by large spherical varicosities, identical to 5-HT axons in the shell of control animals (Fig. $3 B$ ). The absence of transporter protein among these spared, varicose axons confirmed the lack of SERT-IR in the shell (Fig. $3 F$ ). Examples of smooth, thin 5-HT-IR axons could not be detected either in the shell or core of 

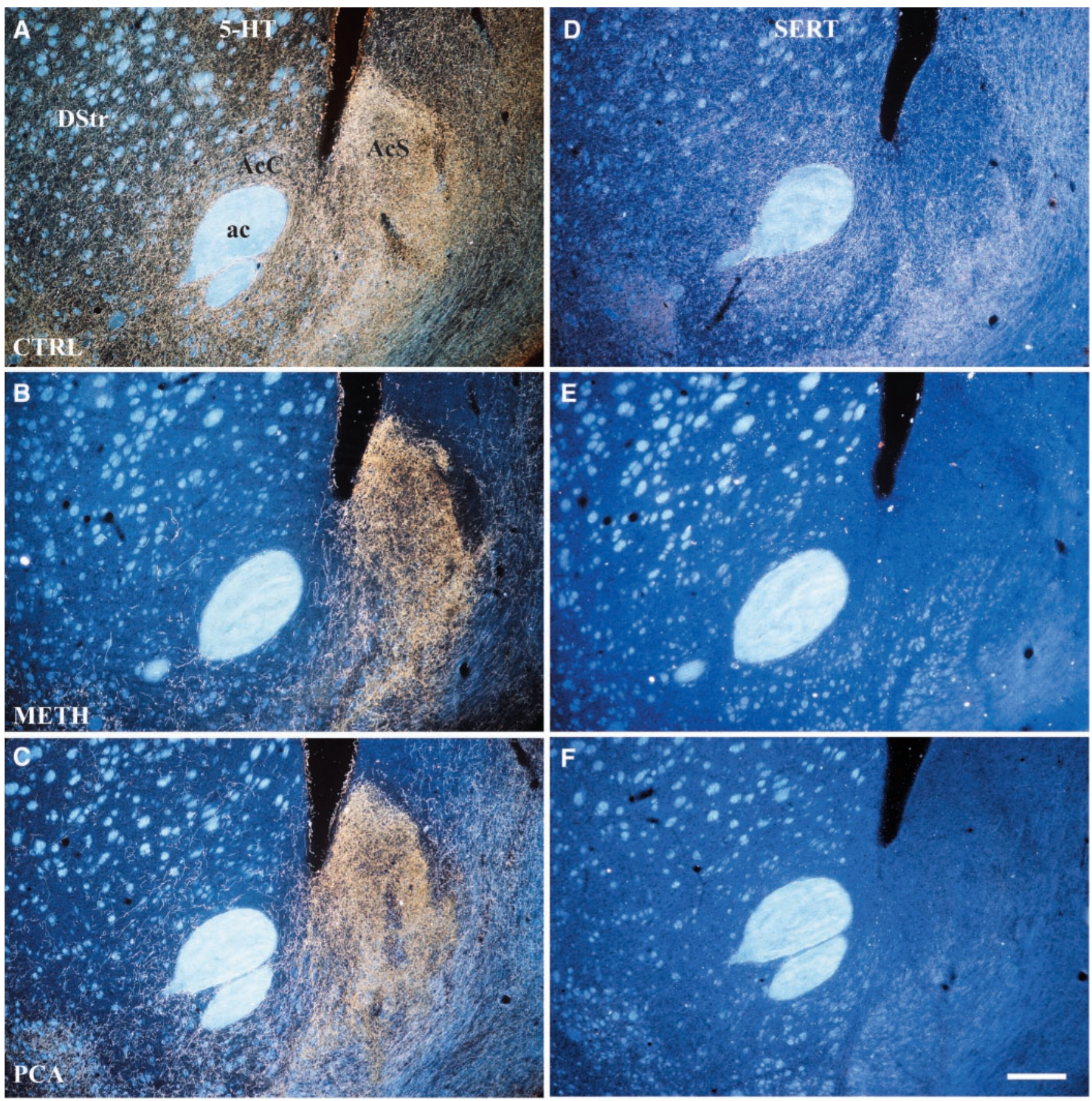

Figure 2. Differential vulnerability of 5-HT axons in NAc shell and core. Dark-field images (coronal) show the effects of Meth $(4 \times 20 \mathrm{mg} / \mathrm{kg})$ or PCA $(2 \times 10 \mathrm{mg} / \mathrm{kg})$ on 5-HT-IR $(A-C)$ and SERT-IR $(D-F)$ axon terminals in the caudal division of the nucleus accumbens (interaural $10.0 \mathrm{~mm})$. In control animals the 5-HT axons in NAc core and dorsal striatum express SERT, whereas most axons in the caudal shell are SERT-negative. After treatment with either drug, 5-HT axons in the core and dorsal striatum are ablated, whereas those in the shell are spared, demonstrating that SERT-negative axons are selectively resistant to amphetamine neurotoxicity. Drug-treated animals were killed $14 \mathrm{~d}$ after treatment, and sections were processed for immunocytochemistry. $A, D$, Saline-treated; $B, E$, Meth-treated; $C, F$, PCA-treated. Scale bar, $300 \mu \mathrm{m}$. $a c$, Anterior commissure; $A c C$, nucleus accumbens core; $A c S$, nucleus accumbens shell; DStr, dorsal striatum. (Note: "dorsal striatum" in the rat refers to the caudate-putamen complex as distinct from ventral striatum.)

NAc or in the dorsal striatum, suggesting that the fine 5-HT axons (which normally express SERT) had been almost totally ablated by Meth.

\section{Dopamine innervation}

In addition to the loss of 5-HT innervation, rats treated with Meth exhibited a decrease in markers for DA axons in the striatum. The density of immunostaining for tyrosine hydroxylase (TH) and for the DATr was substantially diminished in the dorsal striatum 2 weeks after Meth (Fig. 4). The loss of DA axons was greatest in the central portion of the dorsal striatum and extended ventrally to include the core of the accumbens. Spared TH-IR axons (and DATr) remained along the dorsal rim of the striatum (the "subcallosal streak") and in small patches within the dorsal extent of the caudate-putamen (Fig. 4B). The most prominent zone of 

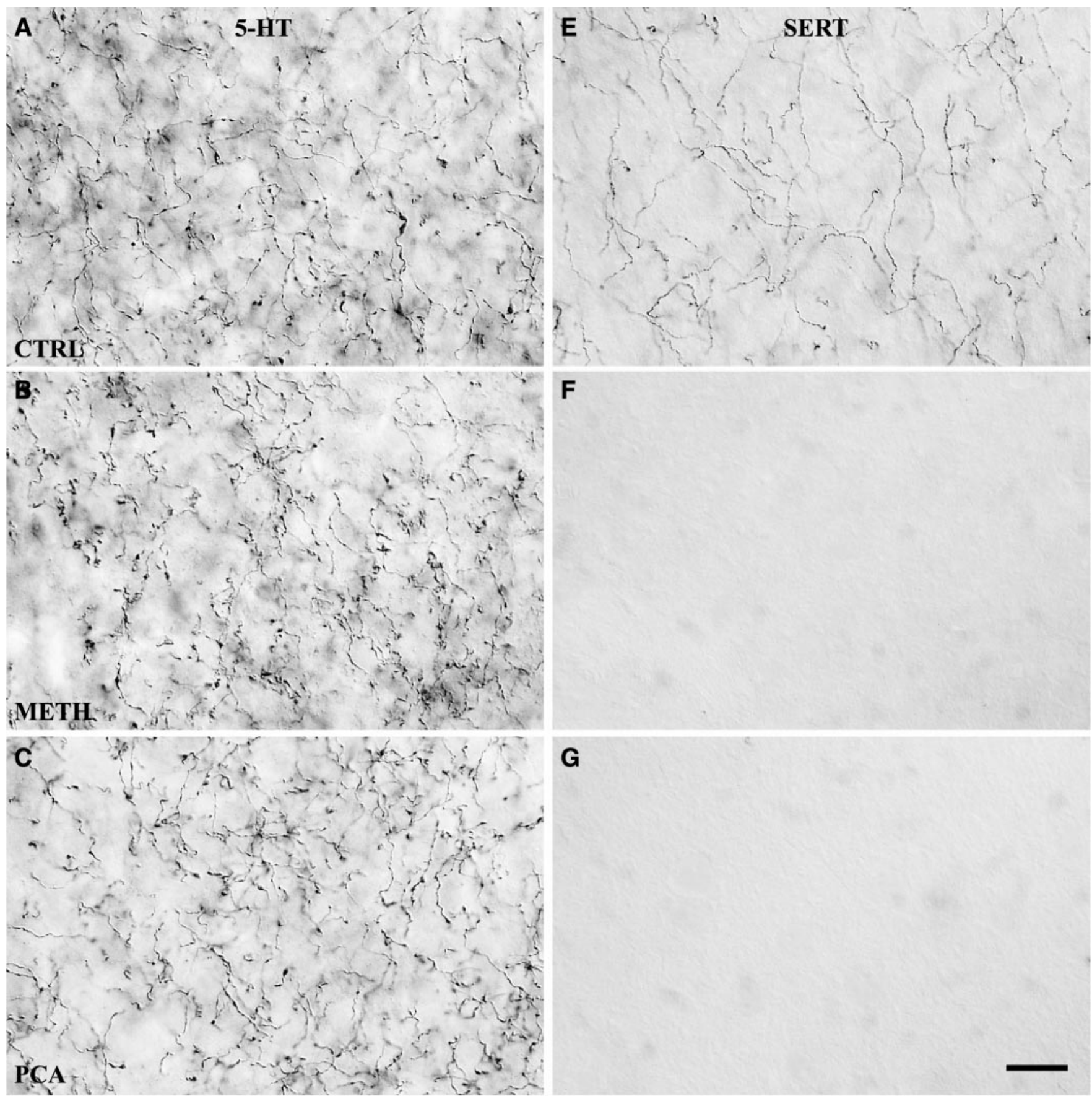

\section{G}
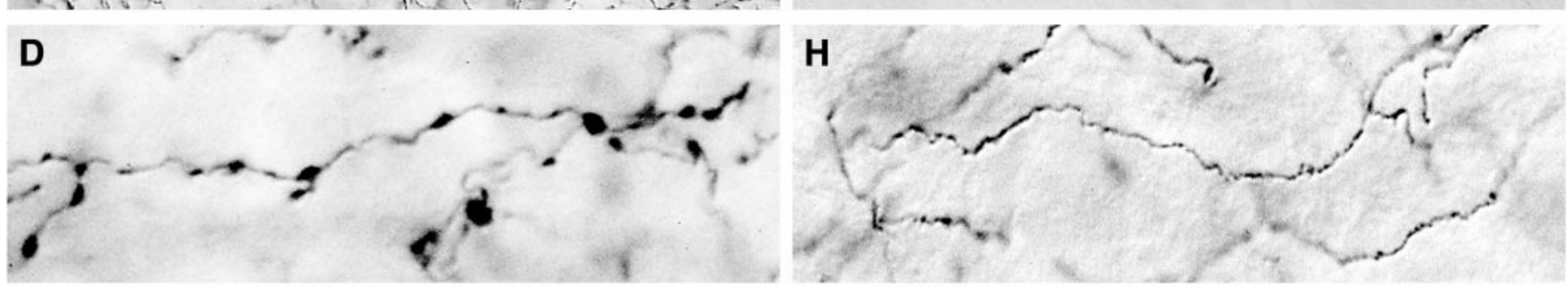

Figure 3. Two morphological types of 5-HT axons in caudal NAc shell differ in SERT expression and in response to Meth and PCA. High-magnification images show the effect of Meth $(4 \times 20 \mathrm{mg} / \mathrm{kg})$ or PCA $(2 \times 10 \mathrm{mg} / \mathrm{kg})$ on 5 -HT-IR $(A-C)$ and SERT-IR $(E-G)$ axon terminals in the caudal shell of the nucleus accumbens. Most 5-HT axons in the NAc shell have large varicosities $(D)$ and lack SERT expression; these axons are unaffected by either drug $(A-C)$. In control rats, a smaller number of thin axons in the shell lack varicosities and express SERT $(E, H)$; the SERT-IR axons are ablated by either drug $(F, G)$. Drug-treated animals were killed $14 \mathrm{~d}$ after drug treatment, and sections were processed by ICC to demonstrate 5-HT or SERT expression. Images were photographed with a $100 \times$ oil immersion objective using DIC. Scale bar, $15 \mu \mathrm{m}$. Enlarged images in the bottom row (at twice the magnification) show examples of varicose 5-HT-IR axon terminals $(D)$ or thin nonvaricose SERT-IR axon terminals $(H)$. $A, E$, Saline-treated; $B$, $F$, Meth-treated; $C, G$, PCA-treated. 

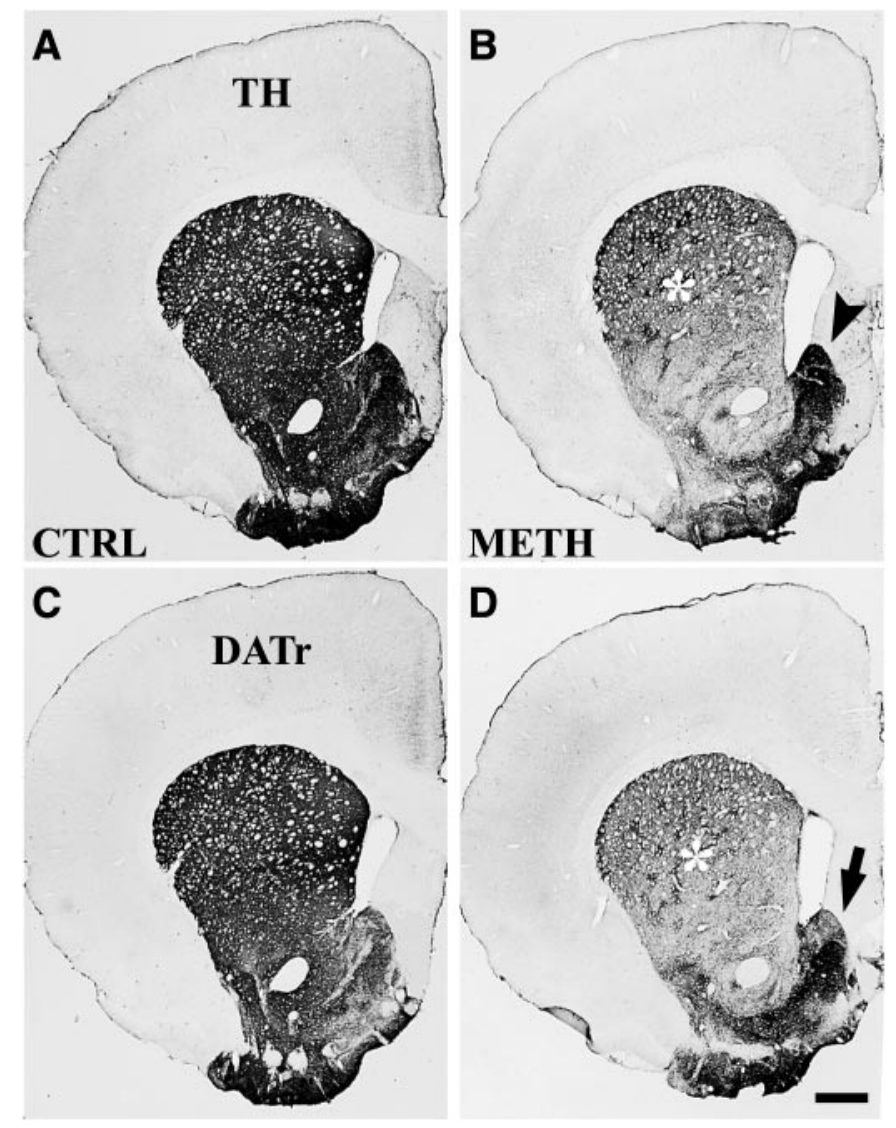

Figure 4. Vulnerability of dopamine axons in striatum and nucleus accumbens to methamphetamine toxicity. Bright-field images show the effect of Meth $(4 \times 20 \mathrm{mg} / \mathrm{kg})$ on TH-IR and DATr-IR axon terminals in dorsal striatum and nucleus accumbens. After Meth treatment, TH-IR is considerably reduced in midstriatum and in the NAc core $(B)$, reflecting DA axonal degeneration (asterisk), whereas in the NAc shell most DA axons are spared (arrowhead). DATr-IR axons $(D)$ showed a similar pattern of axonal degeneration. The location of spared DA axons at this level of the NAc shell (arrow) matches that of drug-resistant 5-HT axons (see Fig. 2B,C). Drug-treated animals were killed $14 \mathrm{~d}$ after treatment, and striatal sections were processed for immunohistochemistry. $A, C$, Saline-treated control; $B, D$, Meth-treated. Scale bar, $700 \mu \mathrm{m}$.

spared TH-IR axons was consistently found in the NAc shell, particularly in the medial portion of the shell that underlies the lateral ventricle and bulges medially into the septum. The zone of DA axon sparing continued into the ventral portion of the NAc shell, which extends ventrolaterally beneath the NAc core. Spared axons in the shell that were immunopositive for the DATr (Fig. $4 D$ ) had the same compartmental distribution as the spared TH-IR axons, although there appeared to be a partial decrease in the density of surviving axons that express the DATr. However, in sections of $40 \mu \mathrm{m}$, it was difficult to detect a loss of DA axons, because the spared axons are heavily stained and of high density.

\section{Comparison of DA and 5-HT innervation}

After Meth or PCA treatment, a comparison was made of the extent of the accumbens shell that contained surviving 5-HT or DA axons, using antisera to 5-HT or TH, respectively (Figs. 2, 4). The regions of the NAc shell that contained numerous spared DA or 5-HT axons were coextensive, particularly in the caudomedial part of the shell. The lateral extension of the shell (under the NAc core) exhibited less sparing of 5-HT than of DA axons (Fig. $2 B$ vs $4 B$ ). More anteriorly, spared DA axons extended further forward
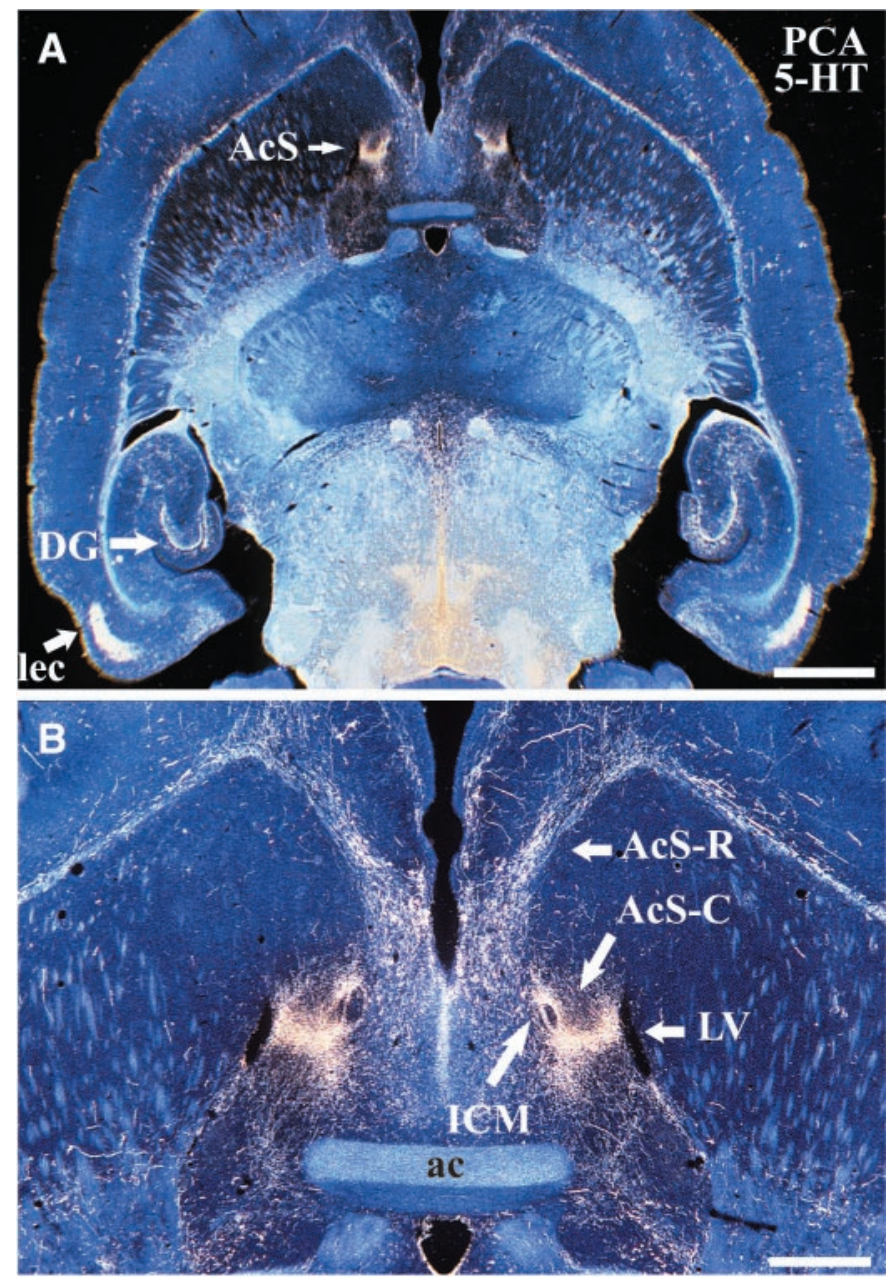

Figure 5. PCA-resistant 5-HT axons have a highly restricted localization in the caudal NAc shell. Low-magnification dark-field images show the distribution of drug-resistant varicose 5-HT-IR (SERT-negative) axon terminals in rat brain after PCA $(2 \times 10 \mathrm{mg} / \mathrm{kg})$ treatment. Note the dense, restricted innervation by spared 5-HT-IR axons in the caudal NAc shell, as in dentate gyrus and entorhinal cortex $(A)$. Higher magnification $(B)$ reveals that the spared 5-HT axons in the caudal shell are situated between the lateral ventricle (laterally) and the island of Calleja magna (medially). Animals were killed $14 \mathrm{~d}$ after PCA treatment, and horizontal sections at the level of the NAc shell were processed for 5-HT immunocytochemistry. Scale bars: $A, 2.0 \mathrm{~mm} ; B, 600 \mu \mathrm{m}$. $a c$, Anterior commissure; $A c S-C$, caudal nucleus accumbens shell; $A c S-R$, rostral nucleus accumbens shell; $D G$, dentate gyrus; ICM, island of Calleja magna; lec, lateral entorhinal cortex; $L V$, lateral ventricle.

into the rostral pole of the NAc than did 5-HT axons. The portion of the NAc densely innervated by drug-resistant 5-HT axons is a discrete, well circumscribed area in the caudal one-third of the shell, where it overlaps the region containing spared DA axons. The localization of drug-resistant 5-HT-IR axons was most clearly delineated in horizontal sections at the level of the NAc shell. After PCA treatment, surviving 5-HT axons were restricted to this area of the shell, $0.8 \mathrm{~mm}$ in length, which is located medial to the NAc core and rostral limb of the anterior commissure, and lies anterior to the bed nucleus of the stria terminalis and the decussation of the anterior commissure (Fig. 5). The zone of spared axons was bounded laterally by the inferior portion of the lateral ventricle and medially by the prominent "island of Calleja magna," the major island of this cell group (Fig. 5B). For comparison with other studies, this region of the caudal shell has been 
termed the "septal pole" of the accumbens or the "cone region" (Voorn et al., 1986; Meredith et al., 1992; Zahm and Brog, 1992; Brog et al., 1993; Heimer et al., 1995).

\section{Effect of PCA on the serotonergic innervation of the NAc}

PCA produced no change in DA innervation (data not shown), but there was an extensive loss of 5-HT axons throughout the forebrain with a pattern of denervation similar to that found after methamphetamine. Fourteen days after PCA treatment $(2 \times 10$ $\mathrm{mg} / \mathrm{kg}$ ), there was a marked loss of 5-HT axons throughout the dorsal striatum extending ventrally to include the core of the accumbens (Fig. 2C). In coronal sections through the striatum, the NAc core was pale and contained very few surviving 5-HT-IR axons. In contrast to the core, the medial part of the accumbens shell remained intensely immunostained for 5-HT, reflecting the survival of most 5-HT axons, which occupied a densely packed zone in the shell (Fig. 2C). The density of spared 5-HT-IR axons in the shell was indistinguishable from that in control rats. The ventrolateral portion of the shell, which extends under the core and anterior commissure, revealed a decrease in density of 5-HT-IR axons. Using high-magnification DIC microscopy, the spared 5-HT-IR axons in the caudal NAc shell (PCA-resistant) were characterized by large, spherical varicosities (Fig. $3 C$ ), identical to the 5-HT axons observed in the shell of control and of Meth-treated animals (Fig. 3A,B). No spared 5-HT-IR axons of the thin, smooth type could be found anywhere in the dorsal striatum or in the accumbens after PCA treatment.

In sections that were processed to detect the 5-HT transporter after PCA, no SERT-IR axons could be found in the dorsal striatum, the NAc core, or the shell (Fig. $2 F$ ). Just as after Meth treatment, the entire striatum including the nucleus accumbens was completely devoid of SERT-IR axons, and the loss of axons that express SERT (Fig. 3G) was confirmed with highmagnification DIC microscopy. Accordingly, the PCA-resistant, varicose 5-HT-IR axons that remain in the NAc shell did not express SERT. All of the SERT-positive axons normally present in the striatum are highly vulnerable to PCA and undergo degeneration. The PCA-sensitive axons include all fine axons that innervate the dorsal striatum and the NAc core in addition to the small number of fine SERT-IR axons that are interspersed with more numerous varicose axons in the shell of NAc (Fig. $3 E$ ).

\section{PCA-induced acute 5-HT depletion in the NAC}

Based on previous results demonstrating that PCA produces acute release of 5-HT from axon terminals, leading to depletion of the transmitter before degeneration occurs (Molliver et al., 1988), tissue sections were obtained $4 \mathrm{hr}$ after PCA to determine whether there was differential release of 5-HT from NAc core or shell. Four hours after a single injection of PCA $(1 \times 10 \mathrm{mg} / \mathrm{kg})$, most axons in the dorsal striatum and the NAc core were no longer immunoreactive for 5-HT, indicating that they were depleted of neurotransmitter (Fig. 6). However, at the same survival time, the caudal NAc shell exhibited intense 5-HT-IR staining (Fig. 6B), and numerous varicose axons in the shell were immunopositive for 5-HT. Adjacent sections for SERT-IR demonstrated that, at this early time point, a normal density of SERT-IR axons remained in core and dorsal striatum, and no signs of axonal loss or degeneration had yet appeared. This material confirmed that $4 \mathrm{hr}$ after PCA, the SERT-IR axons in dorsal striatum and NAc core remained structurally intact (Fig. 6D). This experimental result shows that the PCA-resistant, varicose
5-HT axon terminals in the shell are not acutely depleted of 5-HT and suggests that they may not even release 5-HT in response to PCA treatment. In contrast, the transporter-positive (SERT-IR) terminals (in core) were intact, although depleted of 5-HT, confirming that PCA-induced release is dependent on SERT expression.

\section{5-HT innervation along the anteroposterior axis of the} NAc and effects of Meth or PCA on axon survival

The nucleus accumbens can be divided into at least three rostrocaudal levels that may have different connections, functional properties, and drug responses. In addition to the caudal level described above, we have examined 5-HT innervation and the response to amphetamines in an intermediate portion and at the rostral pole. In saline-treated controls, thin serotonergic axons (5-HT-IR) (Figs. 7A, 8A) were present along the entire rostrocaudal axis of the NAc, and most of these expressed SERT (Figs. $7 D, 8 D)$. Both Meth and PCA administration caused extensive loss of 5-HT axons in the NAc. In the rostral pole and intermediate portion of the NAc, the density of both 5-HT-IR (Figs. $7 B, C, 8 B, C$ ) and SERT-IR (Figs. $7 E, F, 8 E, F$ ) axons was markedly reduced by either drug. After drug treatment, a small number of varicose 5-HT-IR axons remained in the rostral NAc, whereas no SERT-IR axons survived. This result demonstrated that the 5-HT innervation to the rostral two-thirds of NAc consisted primarily of thin, smooth SERT-IR axons that are drugsensitive. In contrast, the caudal NAc shell received the most dense 5-HT innervation, consisting primarily of varicose 5-HT axons that are SERT-negative (Fig. $2 A$ ) in addition to a small number of fine SERT-positive, 5-HT axons. As described above, the varicose, SERT-negative axons were resistant to both Meth (Fig. 2B) and PCA (Fig. 2C) and appeared to be unaffected by either drug.

\section{DISCUSSION}

Certain 5-HT axons in the CNS exhibit selective vulnerability to the neurotoxic effects of several amphetamine derivatives (Molliver et al., 1990). The present study analyzed regional amphetamine toxicity in the NAc to determine the distribution of degenerating 5-HT axons and whether axonal vulnerability may be related to differential expression of the serotonin transporter. The results demonstrate that the NAc is innervated by two types of 5-HT axons that (1) have distinct morphological features, (2) are differentially distributed within the shell and core of the NAc, (3) differ markedly in expression of the serotonin transporter, and (4) differ in vulnerability to amphetamine derivatives. In addition, immediately after amphetamine treatment and before signs of degeneration, (5) the vulnerable 5-HT axons in the NAc core and dorsal striatum are depleted of 5-HT, whereas (6) the drugresistant 5-HT axons form a dense plexus within the NAc shell and retain 5-HT stores. This discrete cluster of surviving 5-HT axon terminals is restricted to the caudal one-third of the medial accumbens shell, where dopamine axons are also spared after methamphetamine.

\section{5-HT innervation of nucleus accumbens}

The 5-HT innervation of NAc in control rats exhibits regional differences in density, SERT expression, and axon morphology. In the caudal NAc shell, 5-HT axon density is higher than in the core or dorsal striatum, in agreement with biochemical data (Deutch and Cameron, 1992). Despite the dense 5-HT innervation, few axons in the shell express SERT. Thus, 5-HT axons in the NAc have two phenotypes: virtually all 5-HT axons in the 

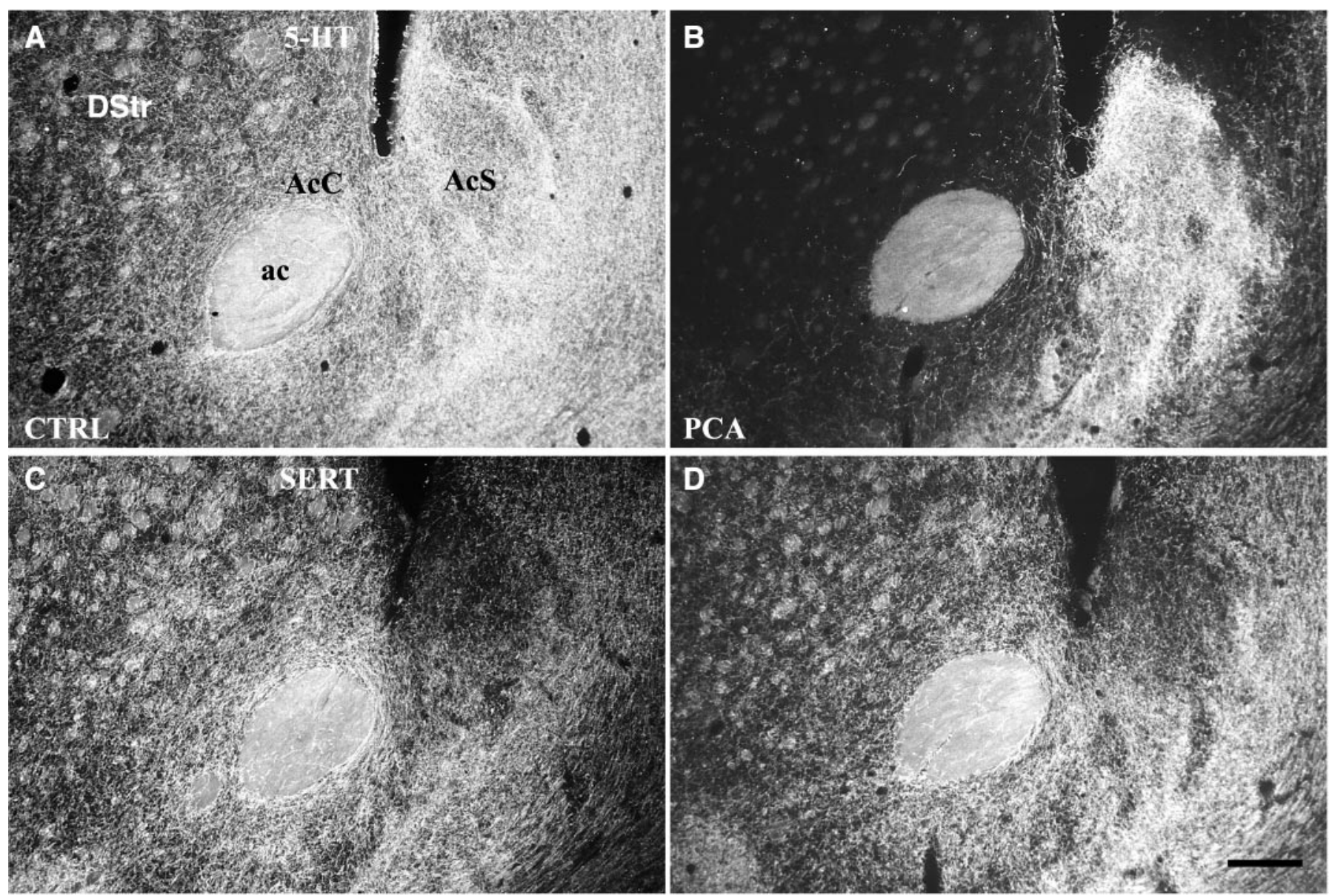

Figure 6. PCA acutely depletes 5-HT from serotonergic axons in NAc core but not in the caudal shell. Dark-field images (coronal) demonstrate PCA-induced $(1 \times 10 \mathrm{mg} / \mathrm{kg}) 5$-HT depletion from axon terminals in the core of nucleus accumbens, whereas axons in the caudal shell remain intensely immunoreactive for 5-HT $(B)$. Although the 5-HT-IR axons in the core are depleted, unaltered SERT-IR staining $(D)$ demonstrates that these axons have not degenerated at this survival time. Animals were killed $4 \mathrm{hr}$ after PCA treatment, and sections were processed for 5-HT and SERT ICC. $A$, $B$, 5-HT-IR axon terminals; $C$, $D$, SERT-IR axon terminals. Scale bar, $300 \mu \mathrm{m}$. $a c$, Anterior commissure; $A c C$, nucleus accumbens core; $A c S$, nucleus accumbens shell; $D$ Str, dorsal striatum. $A$, $C$, Saline-treated; $B, D$, PCA-treated.

core express SERT and are thin and smooth, similar to those in dorsal striatum and cerebral cortex (Mamounas et al., 1991; Axt et al., 1995). In contrast, most 5-HT axons located in the caudal shell lack SERT and exhibit large, spherical varicosities. The morphological differences in 5-HT axons between core and shell confirm a previous ultrastructural study that reported predominantly fine 5-HT axons in the core of NAc compared with varicose axons in the shell (Van Bockstaele and Pickel, 1993). The brainstem origin of 5-HT projections to the nucleus accumbens has not yet been determined, although studies of 5-HT projections to cerebral cortex and olfactory bulb demonstrated that thin drug-sensitive 5-HT axons typically arise from the dorsal raphe, whereas varicose, drug-resistant axons arise from the median raphe (Kosofsky and Molliver, 1987; Mamounas et al., 1991). These two raphe nuclei are likely to encode different signals and have distinct functions because of their separate locations. Although the dichotomous origin of the two axon types may prove to be of general validity, it has not been verified for 5-HT projections to every forebrain region.

\section{Amphetamine neurotoxicity}

A striking result of this study is that Meth and PCA cause profound loss of 5-HT innervation throughout the dorsal striatum and core of NAc but spare most 5-HT axons in the caudal shell of NAc. These findings support a dual 5-HT innervation of NAc with separate projections to the shell and core that differ in axon morphology, SERT expression, and vulnerability to stimulant toxicity. The selective sparing of SERT-negative axons in the shell suggests that SERT expression confers vulnerability to amphetamines and that absence of SERT is neuroprotective. An alternative explanation for the lack of SERT-IR in the shell is that some 5-HT axons might express a different isoform of SERT; however, to our knowledge there is no evidence for multiple isoforms. The specialized, drug-resistant 5-HT axons in the caudal NAc shell are similar to those located in limbic areas of forebrain, namely dentate gyrus of hippocampus and lateral entorhinal cortex (compare Fig. 5) (Mamounas et al., 1991; Axt et al., 1995), suggesting a strong association with limbic system structures.

\section{Overlap of DA and 5-HT projections}

An unexpected result is that amphetamine-resistant DA and 5-HT axons are localized to the NAc shell where they largely overlap. Surviving 5-HT axons are restricted to the caudal-most portion of the shell, whereas spared DA axons innervate a larger area, extending to the rostral pole of NAc. This overlap suggests 

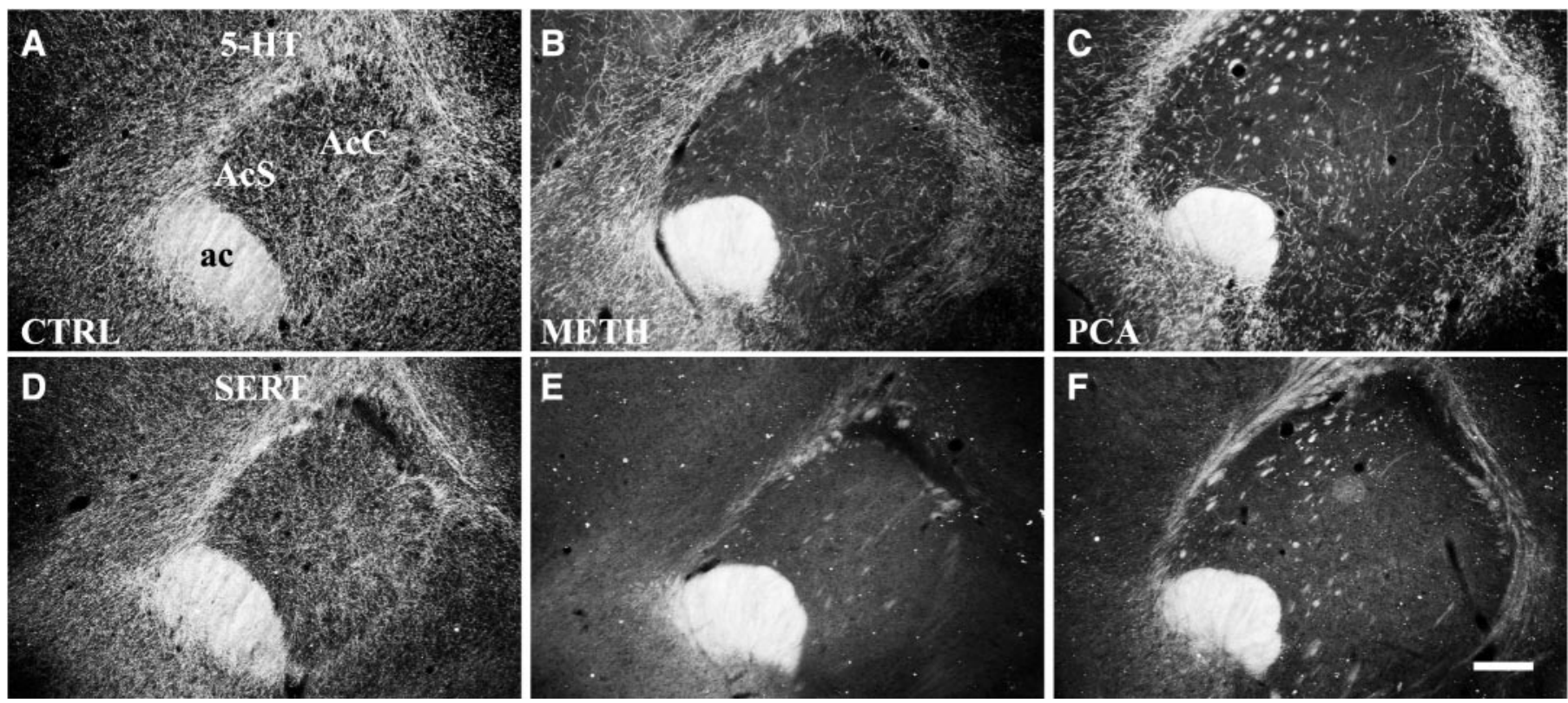

Figure 7. 5-HT innervation of the rostral pole of the nucleus accumbens. Neurotoxic effects of Meth $(4 \times 20 \mathrm{mg} / \mathrm{kg})$ or PCA $(2 \times 10 \mathrm{mg} / \mathrm{kg})$ on 5 -HT-IR $(A-C)$ and SERT-IR $(D-F)$ axon terminals in the rostral pole of the NAc (interaural $11.7 \mathrm{~mm})$ are shown in dark-field images. Most 5-HT axons in the rostral pole are lost after treatment. A small number of 5-HT-IR axons are spared, and these are SERT-negative $(B-F)$. Animals were killed $14 \mathrm{~d}$ after drug treatment, and adjacent sections were processed for 5-HT and SERT immunocytochemistry. $A, D$, Saline-treated; $B, E$, Meth-treated; $C$, $F$, PCA-treated. Scale bar, $300 \mu \mathrm{m}$. $a c$, anterior commissure; $A c C$, nucleus accumbens core; $A c S$, nucleus accumbens shell.
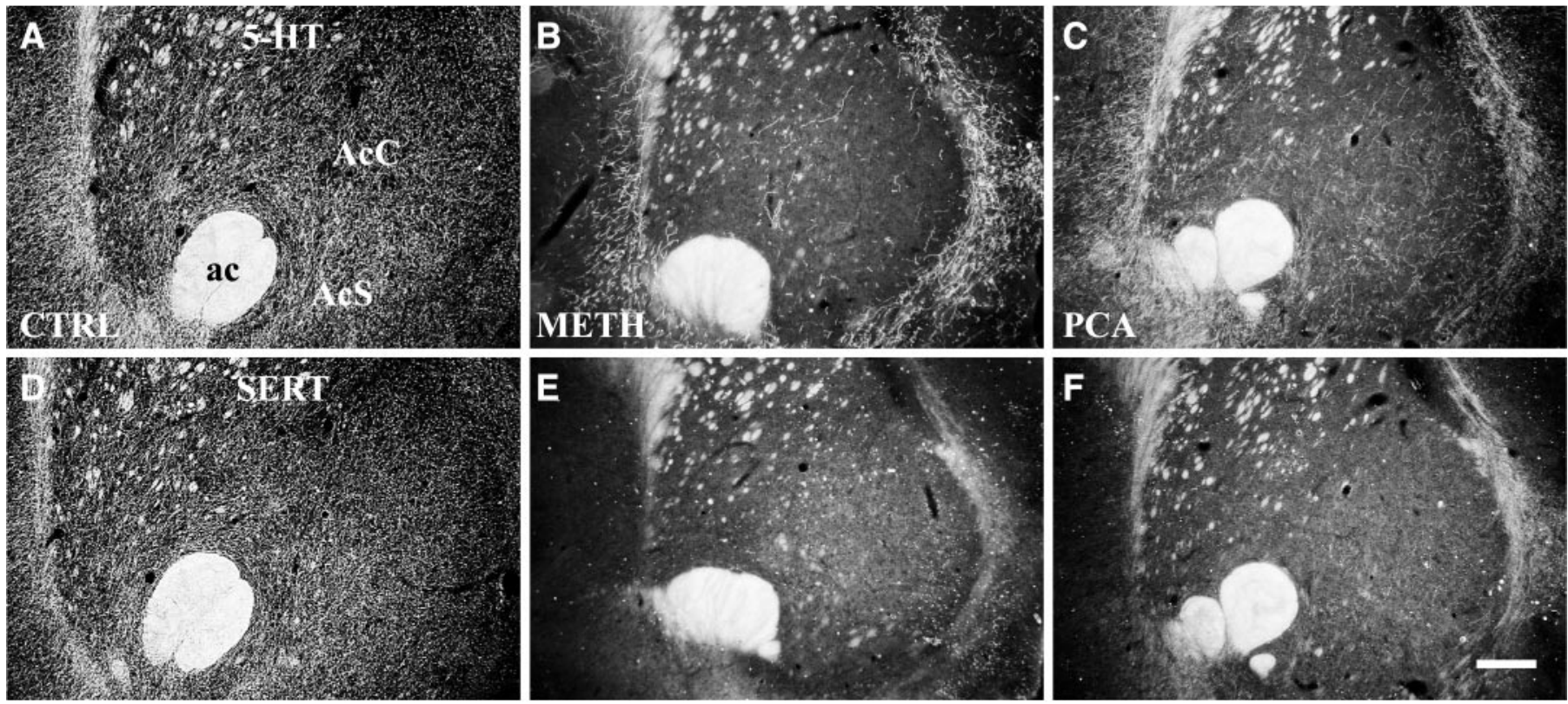

Figure 8. 5-HT innervation of the intermediate division of the nucleus accumbens. Neurotoxic effects of Meth $(4 \times 20 \mathrm{mg} / \mathrm{kg}) \mathrm{or}$ PCA $(2 \times 10 \mathrm{mg} / \mathrm{kg})$ on 5-HT-IR $(A-C)$ and SERT-IR $(D-F)$ axon terminals in the intermediate division of the nucleus accumbens are shown in dark-field images (interaural $11.2 \mathrm{~mm}$ ). Thin, SERT-positive serotonergic axons predominate at this intermediate level of NAc $(A, D)$. As in the rostral pole, most 5-HT axons in the intermediate division are lost after drug treatment. A small number of 5-HT axons are spared, and these are SERT-negative $(B-F)$. Animals were killed $14 \mathrm{~d}$ after drug treatment, and adjacent sections were processed for 5-HT and SERT immunocytochemistry. $A, D$, Saline-treated; $B, E$, Meth-treated; $C$, $F$, PCA-treated. Scale bar, $300 \mu \mathrm{m}$. $a c$, anterior commissure; $A c C$, nucleus accumbens core; $A c S$, nucleus accumbens shell.

that DA and 5-HT axons may interact because 5-HT potentiates DA release, presumably via a presynaptic mechanism (Benloucif and Galloway, 1991; Parsons and Justice, 1993; Yadid et al., 1994; De Deurwaerdère et al., 1996, 1997, 1998). Augmented DA release induced by 5 -HT might potentiate amphetamine neurotoxicity in regions that express SERT, whereas the absence of
SERT within the shell may protect DA axons by limiting 5-HT release in response to psychostimulants. However, this protective mechanism is speculative, because it has not been established that stimulant drugs fail to release 5-HT from axons that lack SERT. The NAc is also innervated by noradrenergic axons from the locus coeruleus (Berridge et al., 1997) and the A2 cell group 
(Delfs et al., 1998), but these sparse noradrenergic axons are unlikely to influence the toxicity, because they are limited to a much smaller area than the spared DA or 5-HT axons.

\section{Amphetamine-induced 5-HT release and depletion}

Binding of amphetamines to the 5-HT transporter is postulated to induce release of 5-HT by reverse transport (Rudnick and Wall, 1992; Levi and Raiteri, 1993; Pontieri et al., 1995; Sulzer et al., 1995; Gudelsky and Nash, 1996; Crespi et al., 1997) and is thought to mediate the neurotoxicity (Fuller et al., 1975; Schmidt and Gibb, 1985; Fuller and Snoddy, 1986; Schmidt and Taylor, 1990). The absence of SERT in varicose 5-HT axons is likely to prevent drug-induced 5-HT release in the NAc shell (White et al., 1994, 1996), protecting SERT-negative axons from toxicity. The acute effects of PCA demonstrate regional differences in 5-HT release and in residual axonal stores of 5-HT. As a result of massive drug-induced release, PCA rapidly depletes most 5-HT axons of neurotransmitter in cerebral cortex, dorsal striatum, and NAc core, yet varicose 5-HT axons in the NAc shell retain large stores of 5-HT. Although this result does not establish that PCA fails to release 5-HT from varicose axons, the absence of SERT, which is the site of drug action, makes it unlikely that amphetamines could release 5-HT from these axons in the shell. Despite acute 5-HT depletion after PCA, SERT-IR axons throughout forebrain exhibit normal density and morphology at $4 \mathrm{hr}$, demonstrating the integrity of these axons at that time and that 5-HT depletion precedes evidence of structural damage.

\section{Rostral NAc and 5-HT innervation}

Three levels of the NAc can be identified: the rostral pole, an intermediate portion, and the caudal NAc, with differences in connectivity along the anteroposterior dimension (Zahm and Brog, 1992; Zahm and Heimer, 1993). The NAc core and shell are most distinct caudally but not readily distinguished rostrally. Most of the rostral pole has projections similar to the NAc core (to motor parts of the basal ganglia), whereas a small medial zone projects to "limbic" targets, as does the caudal shell. Regarding 5-HT afferents, the rostral two-thirds of NAc is less densely innervated than the caudal NAc, and these levels receive different 5-HT axon types. Meth and PCA produce extensive degeneration of axons that co-express 5-HT and SERT, denervating the rostral portion of the accumbens of serotonergic innervation except for those few spared 5-HT axons that are SERT-negative. In contrast, the surviving, dense 5-HT innervation by varicose, SERTnegative axons that are amphetamine-resistant is restricted to the caudal one-third of the NAc shell. These anteroposterior differences in 5-HT innervation of NAc may underlie functional differences in biochemical and locomotor responses to amphetamine applied along the rostrocaudal length of the NAc (King et al., 1997; Heidbreder and Feldon, 1998).

\section{Effects of DA and 5-HT release in NAc}

The dual 5-HT input to separate regions of NAc may explain the heterogeneous electrophysiological effects of methylenedioxymethamphetamine (MDMA) on accumbens neurons (White et al., 1996). Local iontophoresis of MDMA inhibited glutamate-induced firing of NAc neurons, an effect mediated by release of both 5-HT and DA (Obradovic et al., 1996). The more potent inhibition found in the core than the shell indicated greater MDMA-induced 5-HT release in the core, despite more numerous 5-HT axons innervating the shell (White et al., 1995). Those results suggested that 5-HT axons in the NAc core are more sensitive to MDMA than axons in the shell (White et al.,
1996), a hypothesis supported by the present data because psychostimulants are unlikely to release 5-HT in the caudal shell because of the absence of SERT. The resistance of shell axons to neurotoxicity and the lack of 5-HT depletion after PCA provide evidence that SERT-negative axons are insensitive to amphetamine derivatives.

Evidence of stimulant-induced release of DA in the NAc (Di Chiara and Imperato, 1988a,b; Carboni et al., 1989; Pettit and Justice, 1989; Kalivas and Duffy, 1990; Pierce and Kalivas, 1995; Pontieri et al., 1995) has led to the widely held hypothesis that DA release in the NAc shell underlies the addicting and rewarding effects of psychostimulants (Koob et al., 1998). Recent studies support a role for cocaine in inducing both 5-HT and DA release in the Nac, in addition to blocking reuptake (Bradberry et al., 1993; Teneud et al., 1996). The precise localization of neurotransmitter release is difficult to establish with microdialysis, because the probe diameter is substantial, and the zone of diffusion may be large, leading to inconsistencies in locating the site of stimulant-induced release of monoamines. One report that cocaine and amphetamine increase extracellular DA in the NAc shell more than the core shows the dialysis probe in a "central" part of the shell, not in the caudal portion (Pontieri et al., 1995). Another study of amphetamine-induced 5-HT release in a region designated "the caudal shell" (Heidbreder and Feldon, 1998) depicts the dialysis probe at a level anterior to the drug-resistant 5-HT axons described here. The specialized zone of drugresistant, varicose 5-HT axons, easily identified by 5-HT immunocytochemistry, should prove helpful in elucidating the role of DA and 5-HT released by stimulant drugs in the accumbens shell.

The distribution of 5-HT-IR and SERT-IR axons in the NAc has several implications for interpreting the effects of addictive drugs in the nucleus accumbens. Compared with naturally occurring excitation of serotonergic neurons, 5-HT axons in the caudal shell and core are likely to respond differently to psychostimulant drugs, causing the relative amounts of 5-HT released in core and shell to differ under these two conditions. We postulate that drugs such as PCA, MDMA, methamphetamine, and cocaine would release 5-HT selectively in the NAc core but not in the caudal shell, based on the distribution of SERT. In contrast to stimulant drugs, action potentials arising in serotonergic neurons would be conducted along axons to the entire NAc, producing 5-HT release in all subdivisions of this nucleus and yielding the highest extracellular levels of 5-HT in the caudal shell, where 5-HT axon density is greatest. Moreover, postsynaptic effects of any 5-HT released in the caudal shell should be prolonged, because the mechanism for inactivation of 5-HT by reuptake is missing in this region. Removal of extracellular 5-HT from the shell may depend primarily on diffusion or uptake into DA axons. The response to stimulant drugs in rostral NAc should be similar to the core, because most 5-HT axons at rostral levels express SERT. We predict that therapeutic drugs, such as antidepressant 5-HT uptake inhibitors, would produce effects limited to the core and rostral two-thirds of the NAc shell but exert no action in the caudal shell. Identification of the specialized 5-HT innervation in the caudal NAc shell should lead to new studies of synaptic physiology of this region and the mechanism of stimulant-induced release of DA and 5-HT. Future investigations of drug effects on 5-HT axons in the accumbens and of interactions between DA and 5-HT should further elucidate the neurobiological basis of addiction. 


\section{REFERENCES}

Axt KJ, Molliver ME (1991) Immunocytochemical evidence for methamphetamine-induced serotonergic axon loss in the rat brain. Synapse 9:302-313.

Axt KJ, Molliver ME, Qian Y, Blakely RD (1995) Subtypes of 5-HT axons differ in their expression of serotonin transporter. Soc Neurosci Abstr 21:865.

Benloucif S, Galloway MP (1991) Facilitation of dopamine release in vivo by serotonin agonists: studies with microdialysis. Eur J Pharmacol 200:1-8.

Berridge CW, Stratford TL, Foote SL, Kelley AE (1997) Distribution of dopamine- $\beta$-hydroxylase-like immunoreactive fibers within the shell subregion of the nucleus accumbens. Synapse 27:230-241.

Blue ME, Yagaloff KA, Mamounas LA, Hartig PR, Molliver ME (1988) Correspondence between 5-HT2 receptors and serotonergic axons in rat neocortex. Brain Res 453:315-328.

Bradberry CW, Nobiletti JB, Elsworth JD, Murphy B, Jatlow P, Roth RH (1993) Cocaine and cocaethylene: microdialysis comparison of brain drug levels and effects on dopamine and serotonin. J Neurochem 60:1429-1435.

Broening HW, Pu C, Vorhees CV (1997) Methamphetamine selectively damages dopaminergic innervation to the nucleus accumbens core while sparing the shell. Synapse 27:153-160.

Brog JS, Salyapongse A, Deutch AY, Zahm DS (1993) The patterns of afferent innervation of the core and shell in the "accumbens" part of the rat ventral striatum: immunohistochemical detection of retrogradely transported fluoro-gold. J Comp Neurol 338:255-278.

Caine SB (1998) Cocaine abuse: hard knocks for the dopamine hypothesis? Nat Neurosci 1:90-92.

Carboni E, Imperato A, Perezzani L, Di Chiara G (1989) Amphetamine, cocaine, phencyclidine and nomifensine increase extracellular dopamine concentrations preferentially in the nucleus accumbens of freely moving rats. Neuroscience 28:653-661.

Crespi D, Mennini T, Gobbi M (1997) Carrier-dependent and Ca2+dependent 5-HT and dopamine release induced by $(+)$-amphetamine, 3,4-methylendioxymethamphetamine, $p$-chloroamphetamine and (+)fenfluramine. Br J Pharmacol 121:1735-1743.

De Deurwaerdère P, Bonhomme N, Lucas G, Le Moal M, Spampinato U (1996) Serotonin enhances striatal dopamine outflow in vivo through dopamine uptake sites. J Neurochem 66:210-215.

De Deurwaerdère P, L'hirondel M, Bonhomme N, Lucas G, Cheramy A, Spampinato U (1997) Serotonin stimulation of 5-HT4 receptors indirectly enhances in vivo dopamine release in the rat striatum. J Neurochem 68:195-203.

De Deurwaerdère P, Stinus L, Spampinato U (1998) Opposite change of in vivo dopamine release in the rat nucleus accumbens and striatum that follows electrical stimulation of dorsal raphe nucleus: role of 5-HT3 receptors. J Neurosci 18:6528-6538.

Delfs JM, Zhu Y, Druhan JP, Aston-Jones G (1998) Origin of noradrenergic afferents to the shell subregion of the nucleus accumbens: anterograde and retrograde tract-tracing studies in the rat. Brain Res 806:127-140.

Deutch AY, Cameron DS (1992) Pharmacological characterization of dopamine systems in the nucleus accumbens core and shell. Neuroscience 46:49-56.

Di Chiara G, Imperato A (1988a) Drugs abused by humans preferentially increase synaptic dopamine concentrations in the mesolimbic system of freely moving rats. Proc Natl Acad Sci USA 85:5274-5278.

Di Chiara G, Imperato A (1988b) Opposite effects of mu and kappa opiate agonists on dopamine release in the nucleus accumbens and in the dorsal caudate of freely moving rats. J Pharmacol Exp Ther 244:1067-1080.

Eisch AJ, Gaffney M, Weihmuller FB, O’Dell SJ, Marshall JF (1992) Striatal subregions are differentially vulnerable to the neurotoxic effects of methamphetamine. Brain Res 598:321-326.

Fuller RW, Snoddy HD (1986) Fluoxetine enantiomers as antagonists of $p$-chloroamphetamine effects in rats. Pharmacol Biochem Behav 24:281-284.

Fuller RW, Perry KW, Molloy BB (1975) Reversible and irreversible phases of serotonin depletion by 4-chloroamphetamine. Eur J Pharmacol 33:119-124.

Gudelsky GA, Nash JF (1996) Carrier-mediated release of serotonin by 3,4-methylenedioxymethamphetamine: implications for serotonindopamine interactions. J Neurochem 66:243-249.

Heidbreder CA, Feldon J (1998) Amphetamine-induced neurochemical and locomotor responses are expressed differentially across the anteroposterior axis of the core and shell subterritories of the nucleus accumbens. Synapse 29:310-322.

Heimer L, Zahm DS, Churchill L, Kalivas PW, Wohltmann C (1991) Specificity in the projection patterns of accumbal core and shell in the rat. Neuroscience 41:89-125.

Heimer L, Zahm DS, Alheid GF (1995) Basal ganglia. In: The rat nervous system, Ed 2 (Paxinos G, ed), pp 579-628. San Diego: Academic.

Hornung JP, Fritschy JM, Törk I (1990) Distribution of two morphologically distinct subsets of serotoninergic axons in the cerebral cortex of the marmoset. J Comp Neurol 297:165-181.

Jones SR, Gainetdinov RR, Wightman RM, Caron MG (1998) Mechanisms of amphetamine action revealed in mice lacking the dopamine transporter. J Neurosci 18:1979-1986.

Jongen-Relo AL, Groenewegen HJ, Voorn P (1993) Evidence for a multi-compartmental histochemical organization of the nucleus accumbens in the rat. J Comp Neurol 337:267-276.

Jongen-Relo AL, Voorn P, Groenewegen HJ (1994) Immunohistochemical characterization of the shell and core territories of the nucleus accumbens in the rat. Eur J Neurosci 6:1255-1264.

Kalivas PW, Duffy P (1990) Effect of acute and daily cocaine treatment on extracellular dopamine in the nucleus accumbens. Synapse 5:48-58.

King D, Zigmond MJ, Finlay JM (1997) Effects of dopamine depletion in the medial prefrontal cortex on the stress-induced increase in extracellular dopamine in the nucleus accumbens core and shell. Neuroscience 77:141-153.

Koob GF, Sanna PP, Bloom FE (1998) Neuroscience of addiction. Neuron 21:467-476.

Kosofsky BE, Molliver ME (1987) The serotoninergic innervation of cerebral cortex: different classes of axon terminals arise from dorsal and median raphe nuclei. Synapse 1:153-168.

Levi G, Raiteri M (1993) Carrier-mediated release of neurotransmitters. Trends Neurosci 16:415-419.

Lidov HGW, Grzanna R, Molliver ME (1980) The serotonin innervation of the cerebral cortex in the rat-an immunohistochemical analysis. Neuroscience 5:207-227.

Mamounas LA, Mullen CA, O'Hearn E, Molliver ME (1991) Dual serotonergic projections to forebrain in the rat: morphologically distinct 5-HT axon terminals exhibit differential vulnerability to neurotoxic amphetamine derivatives. J Comp Neurol 314:558-586.

Meredith GE, Agolia R, Arts MPM, Groenewegen HJ, Zahm DS (1992) Morphological differences between projection neurons of the core and shell in the nucleus accumbens of the rat. Neuroscience 50:149-162.

Meredith GE, Pattiselanno A, Groenewegen HJ, Haber SN (1996) Shell and core in monkey and human nucleus accumbens identified with antibodies to calbindin-D28k. J Comp Neurol 365:628-639.

Mijnster MJ, Raimundo AG, Koskuba K, Klop H, Docter GJ, Groenewegen HJ, Voorn P (1997) Regional and cellular distribution of serotonin 5-hydroxytryptamine2a receptor mRNA in the nucleus accumbens, olfactory tubercle, and caudate putamen of the rat. J Comp Neurol 389:1-11.

Molliver ME, Stratton K, Carr P, Grzanna R, Baraban JM (1988) Contrasting in vitro and in vivo effects of $p$-chloroamphetamine (PCA) on 5-HT axons: immunocytochemical studies in hippocampal slices. Soc Neurosci Abstr 14:210.

Molliver ME, Berger UV, Mamounas LA, Molliver DC, O'Hearn E, Wilson MA (1990) Neurotoxicity of MDMA and related compounds: anatomic studies. Ann NY Acad Sci 600:640-664.

Obradovic T, Imel KM, White SR (1996) Methylenedioxymethamphetamine-induced inhibition of neuronal firing in the nucleus accumbens is mediated by both serotonin and dopamine. Neuroscience 74:469-481.

O’Hearn E, Battaglia G, De Souza EB, Kuhar MJ, Molliver ME (1988) Methylenedioxyamphetamine (MDA) and methylenedioxymethamphetamine (MDMA) cause selective ablation of serotonergic axon terminals in forebrain: immunocytochemical evidence for neurotoxicity. J Neurosci 8:2788-2803.

Parsons LH, Justice Jr JB (1993) Perfusate serotonin increases extracellular dopamine in the nucleus accumbens as measured by in vivo microdialysis. Brain Res 606:195-199.

Paxinos G, Watson C (1998) The rat brain in stereotaxic coordinates, Ed 4. San Diego: Academic.

Pettit HO, Justice Jr JB (1989) Dopamine in the nucleus accumbens 
during cocaine self-administration as studied by in vivo microdialysis. Pharmacol Biochem Behav 34:899-904.

Pierce RC, Kalivas PW (1995) Amphetamine produces sensitized increases in locomotion and extracellular dopamine preferentially in the nucleus accumbens shell of rats administered repeated cocaine. J Pharmacol Exp Ther 275:1019-1029.

Pontieri FE, Tanda G, Di Chiara G (1995) Intravenous cocaine, morphine, and amphetamine preferentially increase extracellular dopamine in the "shell" as compared with the "core" of the rat nucleus accumbens. Proc Natl Acad Sci USA 92:12304-12308.

Ricaurte GA, Schuster CR, Seiden LS (1980) Long-term effects of repeated methylamphetamine administration on dopamine and serotonin neurons in the rat brain: a regional study. Brain Res 193:153-163.

Ricaurte GA, Guillery RW, Seiden LS, Schuster CR, Moore RY (1982) Dopamine nerve terminal degeneration produced by high doses of methylamphetamine in the rat brain. Brain Res 235:93-103.

Rocha BA, Fumagalli F, Gainetdinov RR, Jones SR, Ator R, Giros B, Miller GW, Caron MG (1998) Cocaine self-administration in dopamine-transporter knockout mice. Nat Neurosci 1:132-137.

Rudnick G, Wall SC (1992) $p$-Chloroamphetamine induces serotonin release through serotonin transporters. Biochemistry 31:6710-6718.

Schmidt CJ, Gibb JW (1985) Role of the serotonin uptake carrier in the neurochemical response to methamphetamine: effects of citalopram and chlorimipramine. Neurochem Res 10:637-648.

Schmidt CJ, Taylor VL (1990) Reversal of the acute effects of 3,4methylenedioxymethamphetamine by 5-HT uptake inhibitors. Eur J Pharmacol 181:133-136.

Schroeter S, Levey AI, Blakely R D (1997) Polarized expression of the antidepressant-sensitive serotonin transporter in epinephrinesynthesizing chromaffin cells of the rat adrenal gland. Mol Cell Neurosci 9:170-184.

Steinbusch HWM (1981) Distribution of serotonin-immunoreactivity in the central nervous system of the rat-cell bodies and terminals. Neuroscience 6:557-618.

Steinbusch HWM, Nieuwenhuys R, Verhofstad AAJ, van der Kooy D (1981) The nucleus raphe dorsalis of the rat and its projection upon the caudatoputamen. A combined cytoarchitectonic, immunohistochemical and retrograde transport study. J Physiol (Paris) 77:157-174.

Sulzer D, Rayport S (1990) Amphetamine and other psychostimulants reduce $\mathrm{pH}$ gradients in midbrain dopaminergic neurons and chromaffin granules: a mechanism of action. Neuron 5:797-808.

Sulzer D, Maidment NT, Rayport S (1993) Amphetamine and other weak bases act to promote reverse transport of dopamine in ventral midbrain neurons. J Neurochem 60:527-535.

Sulzer D, Chen TK, Lau YY, Kristensen H, Rayport S, Ewing AG (1995) Amphetamine redistributes dopamine from synaptic vesicles to the cytosol and promotes reverse transport. J Neurosci 15:4102-4108.
Swanson LW (1982) The projections of the ventral tegmental area and adjacent regions: a combined fluorescent retrograde tracer and immunofluorescence study in the rat. Brain Res Bull 9:321-353.

Swanson LW (1998) Brain maps: structure of the rat brain, Ed 2. Amsterdam: Elsevier.

Teneud LM, Baptista T, Murzi E, Hoebel BG, Hernandez L (1996) Systemic and local cocaine increase extracellular serotonin in the nucleus accumbens. Pharmacol Biochem Behav 53:747-752.

Van Bockstaele EJ, Pickel VM (1993) Ultrastructure of serotoninimmunoreactive terminals in the core and shell of the rat nucleus accumbens: cellular substrates for interactions with catecholamine afferents. J Comp Neurol 334:603-617.

Voorn P, Jorritsma-Byham B, Van Dijk C, Buijs RM (1986) The dopaminergic innervation of the ventral striatum in the rat: a light- and electron-microscopical study with antibodies against dopamine. J Comp Neurol 251:84-99.

Voorn P, Gerfen CR, Groenewegen HJ (1989) Compartmental organization of the ventral striatum of the rat: immunohistochemical distribution of enkephalin, substance $\mathrm{P}$, dopamine, and calcium-binding protein. J Comp Neurol 289:189-201.

White SR, Duffy P, Kalivas PW (1994) Methylenedioxymethamphetamine depresses glutamate-evoked neuronal firing and increases extracellular levels of dopamine and serotonin in the nucleus accumbens in vivo. Neuroscience 62:41-50.

White SR, Imel KM, Obradovic T (1995) Long-term attenuation of inhibitory effects of serotonin and dopamine on glutamate-evoked firing of nucleus accumbens cells following repeated injections of methylenedioxymethamphetamine (MDMA). Soc Neurosci Abstr 21:969.

White SR, Obradovic T, Imel KM, Wheaton MJ (1996) The effects of methylenedioxymethamphetamine (MDMA, "Ecstasy") on monoaminergic neurotransmission in the central nervous system. Prog Neurobiol 49:455-479.

Wise RA (1996) Addictive drugs and brain stimulation reward. Annu Rev Neurosci 19:319-340.

Yadid G, Pacak K, Kopin IJ, Goldstein DS (1994) Endogenous serotonin stimulates striatal dopamine release in conscious rats. J Pharmacol Exp Ther 270:1158-1165.

Zaborszky L, Alheid GF, Beinfeld MC, Eiden LE, Heimer L, Palkovits M (1985) Cholecystokinin innervation of the ventral striatum: a morphological and radioimmunological study. Neuroscience 14:427-453.

Zahm DS, Brog JS (1992) On the significance of subterritories in the "accumbens" part of the rat ventral striatum. Neuroscience 50:751-767.

Zahm DS, Heimer L (1993) Specificity in the efferent projections of the nucleus accumbens in the rat: comparison of the rostral pole projection patterns with those of the core and shell. J Comp Neurol 327:220-232. 